\title{
INVERSION OF GEODETIC DATA. PART II. OPTIMAL MODEL OF CONJUGATE FAULT SYSTEM FOR THE 1927 TANGO EARTHQUAKE
}

\author{
Mitsuhiro MAtSU'URA \\ Geophysical Institute, Faculty of Science, \\ University of Tokyo, Tokyo, Japan
}

(Received March 14, 1977)

\begin{abstract}
Parmanent changes in displacement due to the 1927 Tango earthquake $(M=7.5)$ are analyzed by using the method of "geodetic data inversion" developed in a previous paper (Part I; MATSU'URA, 1977), and a set of optimal source parameters is obtained for a system of conjugate faults, the Gomura and the Yamada.

Deformation fields are modelled by a multiple-fault system composed of several dimensional faults in an elastic half-space, and the optimization of model parameters is accomplished through a process of successive iteration of inversions for 85 triangulation and 25 levelling data around the seismic faults.

The optimal fault parameters obtained are $D$ (dislocation) $=3.7 \mathrm{~m}, \delta$ (dipangle $)=64^{\circ} \mathrm{E}, \lambda$ (slip direction $)=-8^{\circ}, L($ length $)=33 \mathrm{~km}, W($ width $)=19 \mathrm{~km}$, $d$ (depth) $=0.4 \mathrm{~km}$ and $\theta$ (strike of fault $)=\mathrm{N} 24^{\circ} \mathrm{W}$ for the Gomura fault, and $D=1.8 \mathrm{~m}, \delta=58^{\circ} \mathrm{N}, \lambda=120^{\circ}, L=15 \mathrm{~km}, W=9 \mathrm{~km}, d=0.2 \mathrm{~km}$ and $\theta=\mathrm{N} 77^{\circ} \mathrm{E}$ for the Yamada fault, where the slip direction is measured counterclockwise from horizon on the fault plane. These results indicate that the two seismic faults constitute a system of conjugate faults caused by a single stress system of NW-SE compression.

A computer program for the geodetic data inversion is completed, by which a set of optimal source parameters of seismic and aseismic events can be obtained from the observed static displacement data.
\end{abstract}

\section{Introduction}

This is the second paper of a series of papers dealing with the "geodetic data inversion" for source parameters of seismic and aseismic events. A practical method of finding the optimal fault-plane solutions and evaluating the degree of their reliabilities from a set of inaccurate geodetic data has been developed in Part I (MATsu'URA, 1977) of this series. In the present paper, the method of geodetic data inversion is applied to the observed static displacement data associated with the 1927 Tango earthquake.

The Tango earthquake $(M=7.5)$ occurred in the Japan Sea side of Honshu 
island on March 7, 1927. Detailed investigations have been made on the deformation of the earth's crust by TsuBor (1930a, b, 1931, 1932), and on the aftershock distributions by NASU (1929) caused by this earthquake. At the time of the earthquake, two remarkable seismic faults, the Gomura and the Yamada, appeared in the central area of the Tango district.

For the Gomura fault, several fault-plane studies have been made to interpret the horizontal displacement data near the northwest coastline of the Tango peninsula by using highly idealized models (KaSAHARA, 1957, 1958; ChInNery, 1961; WALSH, 1969). These authors pointed out that the Gomura fault is a predominantly left-lateral slip on a nearly vertical (steeply dipping westward) plane with a width of about $15 \mathrm{~km}$. On the other hand, the Yamada fault has received less attention except for the investigation by WALSH (1969). From levelling data, he estimated that the faulting is a reverse type on a plane dipping northward with an angle of about $40^{\circ}$. This agrees with a result based on the study of aftershocks by NASU (1929), but differs from that based on the field observations, such as a normal faulting with a dip-angle of $85^{\circ} \mathrm{S}$, by Tsubor (1930a).

All of these fault-plane solutions were obtained by searching for a set of the best fitting parameters to the observations in some least squares sense, under the assumption that the data are contaminated by some kind of systematic errors, e.g. the effect of the rotation of the base line by the accumulation of tectonic strain or the anelastic deformation of the northeast side block. When estimating the source parameters of a seismic event from geodetic data, it is not avoidable that the resulting solutions are involved in some degrees of non-uniqueness, because the data are finite in number and contain random errors, and more fundametally, because there exist some deficiencies in the mathematical model concerned. Therefore, it is needed to evaluate the degree of reliability of the result as well as to find the optimal solution in a reasonable and systematic fashion.

Recently, several attempts to apply the inversion technique to the analysis of geodetic data have been made to estimate the source parameters of seismic events. For example, AlEwINE and Jordan (1973) analyzed the vertical displacements due to the occurrence of the 1971 San Fernando earthquake by taking only the amount of the slip along a complex fault system as a variable parameter. For a point dislocation source model, Jovanovich (1975) has developed an inversion method to estimate the source parameters of seismic events from static strain data, and applied it to the cases of the $1971 \mathrm{San}$ Fernando and the 1969 Gifu earthquake.

However, for the analysis of geodetic data in the near-field, it is necessary that the deformation fields are modelled by a dimensional fault with various variables, such as the magnitude and direction of the slip, the length, 
width, depth and location of the fault, the dip-angle and strike direction. In the present study, the method of geodetic data inversion is applied to the case of the 1927 Tango earthquake, and the nature of the conjugate faults, the Gomura and the Yamada, is discussed in detail.

\section{Observations and Initial Model}

Concerning the 1927 Tango earthquake, a large amount of measurements of permanent changes in displacement around two remarkable seismic faults, the Gomura and the Yamada, has been reported by Tsubor (1930a, b, 1931, 1932). Among them, the data used in the present analysis are summarized in Fig. 1.

The Gomura fault consists of several parallel cracks which extend out in to the Sea of Japan. The western block of the fault moved southward about $2.5 \mathrm{~m}$ and was elevated $0.7 \mathrm{~m}$ relative to the eastern block. The motion is predominantly left-lateral. On the other hand, the Yamada fault seems to stretch discontinuously from the base of the Tango peninsula to the northeast. The amount of the slip along this fault is somewhat smaller than that along the Gomura fault, that is, the southern side of the fault subsided by about $1.0 \mathrm{~m}$ and moved $0.7 \mathrm{~m}$ westward relative to the northern side. The horizontal motion is right-lateral.

Horizontal displacement data $(1927-1884 \sim 1889)$ were obtained for over 270 triangulation points (6 first order, 41 second order and 226 third order triangulation points) in a series of post-seismic surveys. The gross feature of the observed horizontal displacement field suggests that the Gomura fault is a nearly vertical, predominantly left-lateral slipping which extends over a distance of $30 \mathrm{~km}$ in a direction of $\mathrm{N} 30^{\circ} \mathrm{W}$. On the other hand, little information on the nature of the Yamada fault is obtained from the pattern of the horizontal displacement field alone, except that the slip has a right-lateral component.

Relative changes in the vertical displacement (1927-1888) were measured at about 50 bench marks along the levelling route which extends to a region more than $30 \mathrm{~km}$ from the epicenter where the changes in the diplacement gradient were slight. The results of levelling indicate that the Yamada fault is not a normal, but a reverse type of faulting with a comparatively large dip-slip component of about $1.0 \mathrm{~m}$ on a plane dipping somewhat loosely to the north.

The distribution of aftershocks also gives us useful information on the extension of the main faulting. The aftershocks associated with the Tango earthquake are roughly divided into two groups which correspond to two remarkable seismic faults, the Gomura and the Yamada, respectively. On a 


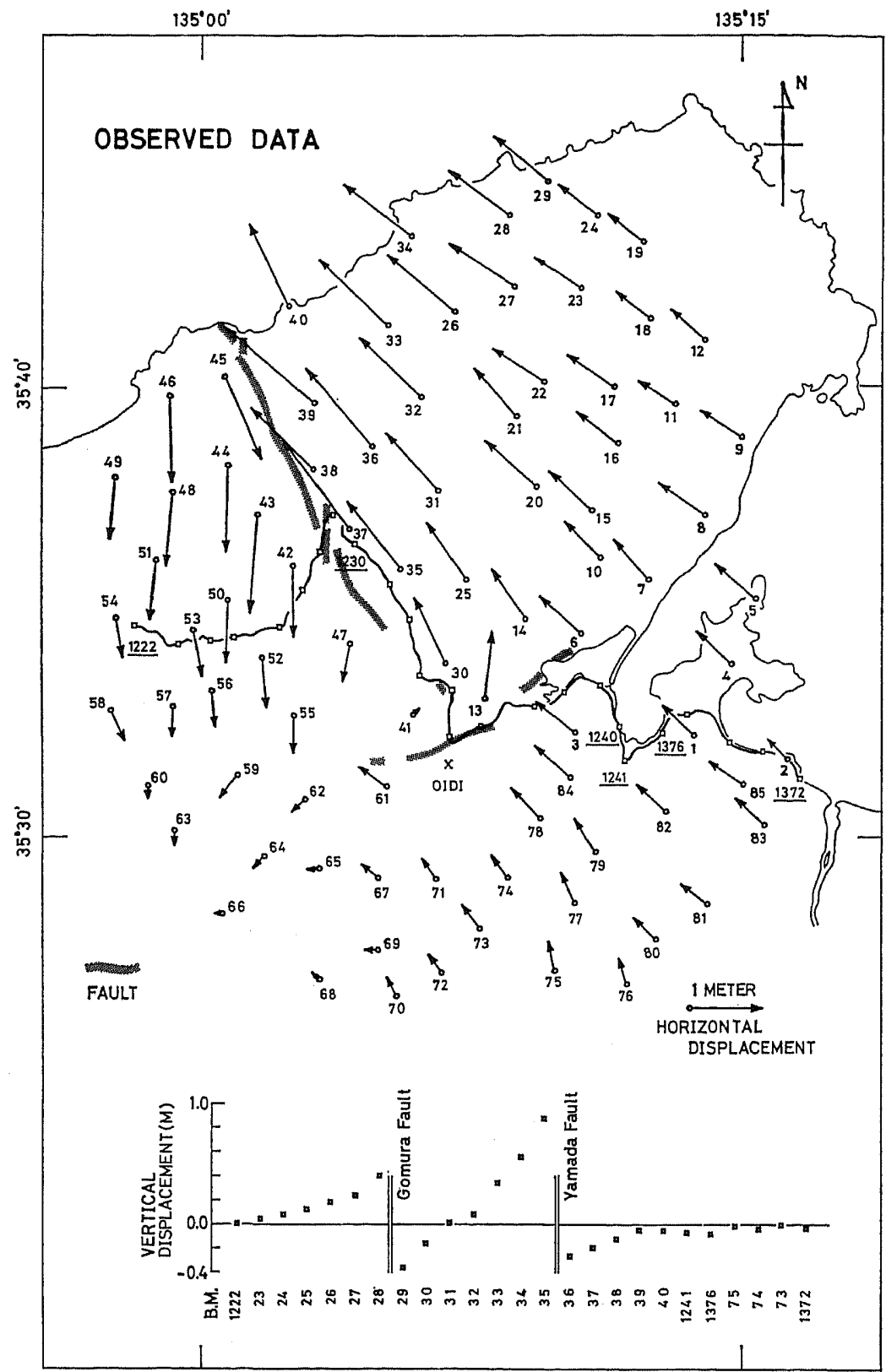

Fig. 1. Static deformations due to the 1927 Tango earthquake. Only 85 triangulation and 25 levelling data are shown, which are used in the present analysis. Each station number corresponds to that in Table 2. 


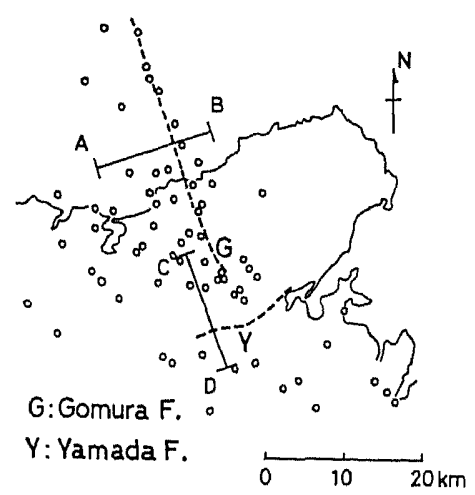

(a)

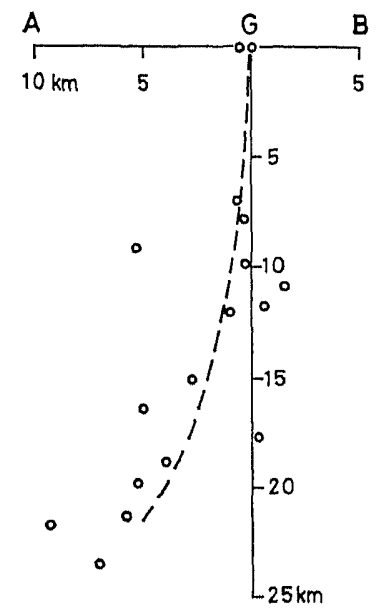

(b)

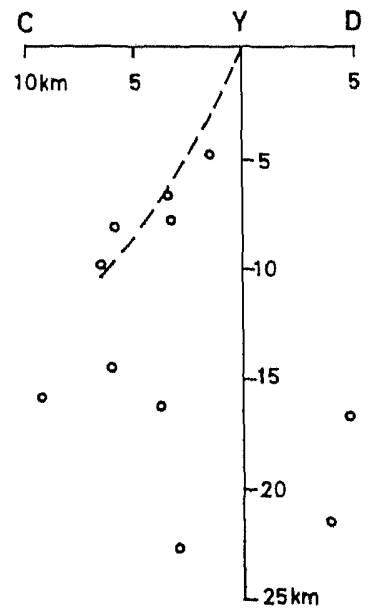

(c)

Fig. 2. Distribution of aftershocks for March 12, 1927-July 31, 1928 (reproduced from NAsu (1929) after some abbreviation). (a) Projection of seismic foci on the earth's surface. (b) Projection of seismic foci on the vertical plane normal to the Gomura fault. (c) Projection of seismic foci on the vertical plane normal to the Yamada fault.

reasonable assumption that the region accompanied with the occurrence of aftershocks almost coincides with the extension of the main faulting, we are able to expect the gross aspects of two main faultings from the aftershock distributions as follows:

The Gomura fault seems to extend out in to the Sea of Japan over a length of $30 \mathrm{~km}$ in the direction of $\mathrm{N} 30^{\circ} \mathrm{W}$ (Fig. 2(a)). For the Yamada fault, the area of aftershocks spreads from the base of the Tango peninsula to the west (Fig. 2(a)). Projections of the aftershocks on the vertical plane normal to each fault suggest that the Gomura fault is nearly vertical (Fig. 2(b)), and the dip-angle of the Yamada fault is about $50^{\circ} \mathrm{N}$ (Fig. 2(c)). 
Table 1. Adopted initial model (Model I) and the fault-plane solutions estimated by the previous investigators.

Gomura fault

\begin{tabular}{|c|c|c|c|c|c|c|c|c|}
\hline & $D(\mathrm{~m})$ & $\grave{\partial}$ & $\lambda$ & $W(\mathrm{~km})$ & $d(\mathrm{~km})$ & $a_{0}$ & $b_{0}$ & $a_{1}$ \\
\hline Model I & 3.0 & $80^{\circ} \mathrm{E}$ & $20^{\circ}$ & 20 & 0.3 & -1.85 & 3.30 & -0.35 \\
\hline Tsubor (1930a) & 2.5 & $64^{\circ} \mathrm{W}$ & $20^{\circ}$ & - & 0.0 & \multicolumn{3}{|c|}{$\theta=\mathrm{N} 30^{\circ} \mathrm{W}$} \\
\hline NASU (1929) & - & $70^{\circ} \mathrm{W}$ & - & $\leq 25^{*}$ & - & $\theta=\mathrm{N} 30$ & $0^{\circ} \mathrm{W}, *$ & $L \geq 30 \mathrm{~km}^{*}$ \\
\hline KASAHARA (1957) & 3.0 & $90^{2}$ & $0^{\circ}$ & 15 & 0.0 & $\theta=\mathrm{N} 30$ & $0^{\circ} \mathrm{W}$ & $L=30 \mathrm{~km}$ \\
\hline Chinnery (1961) & 3.0 & $90^{\circ}$ & $0^{\circ}$ & $10 \sim 12$ & 0.0 & $\theta=\mathrm{N} 3 \mathrm{C}$ & $0^{\circ} \mathrm{W}, *$ & $L=36 \mathrm{~km}$ \\
\hline WALSH (1969) & 3.0 & $70^{\circ} \sim 75^{\circ} \mathrm{W}$ & - & - & 0.0 & $\theta=\mathrm{N} 30$ & $0^{\circ} \mathrm{W}^{*}$ & \\
\hline
\end{tabular}

Yamada fault

\begin{tabular}{lccccccccc}
\hline & $D(\mathrm{~m})$ & $i$ & $\lambda$ & $W(\mathrm{~km})$ & $d(\mathrm{~km})$ & $a_{0}$ & $b_{0}$ & $a_{1}$ & $b_{1}$ \\
\hline Model I & 1.5 & $70^{\circ} \mathrm{N}$ & $120^{\circ}$ & 20 & 0.1 & -0.85 & -0.30 & 0.55 & 0.50 \\
TsuboI (1930a) & 1.4 & $85^{\circ} \mathrm{S}$ & $-120^{\circ}$ & - & 0.0 & $\theta=\mathrm{N} 55^{\circ} \mathrm{E}$ & & \\
NASU (1929) & - & $40^{\circ} \sim 50^{\circ} \mathrm{N}$ & - & $\leq 20^{*}$ & - & $\theta=\mathrm{N} 60^{\circ} \mathrm{E}^{*}$ & & \\
WALSH (1969) & 1.3 & $40^{\circ} \mathrm{N}$ & - & - & 0.0 & $\theta=\mathrm{N} 60^{\circ} \mathrm{E}^{*}$ & & \\
\hline
\end{tabular}

Notes: $D$; magnitude of dislocation. $\delta$; dip-angle. $\lambda$; slip direction measured counterclockwise from horizon on the fault plane. $W$; fault width. $d$; depth of upper fault edge. $\left(a_{0}, b_{0}\right)$ and $\left(a_{1}, b_{1}\right)$; location of the upper-right and -left fault corner on the $X-Y$ coordinates with a unit of $10 \mathrm{~km}$, where the origin is fixed to a point $\left(35.53^{\circ} \mathrm{N}, 135.11^{\circ} \mathrm{E}\right)$, and the $X$ - and $Y$-axis are taken parallel to the east- and north-direction respectively. $L$; fault length. $\theta$; strike direction. *; rough estimation.

On the basis of these investigations about the observed data, an initial model of conjugate fault system (referred to as Model I hereafter) is adopted as shown in Table 1, in which the fault-plane solutions estimated by the previous investigators are also presented for comparison with Model I. It is noted that we do not assume any kind of systematic error associated with the observed data in the selection of the initial model. Of course, the possibility of a systematic contamination of the data cannot be denied, but we do not have any kind of reliable information for the data to remove such contamination (Marsuzawa, 1964). Therefore, it is reasonable to assume that the errors associated with data, such as observational errors, some systematic contaminations caused by the occurrence of the events beyond our concern and the deficiencies in the adopted mathematical model, are non-singular, random and finite.

In the present study, only 85 horizontal and 25 vertical displacement data shown in Fig. 1 are used, because of the occurrence of a faulting due to the Tazima earthquake $\left(35.7^{\circ} \mathrm{N}, 134.8^{\circ} \mathrm{E} ; M=7.0\right.$; May 23,1925$)$ in the western part close to the area under consideration, and more practically, because of a restriction on the memory capacity of the computer. Each observed datum 
Table 2.1. Horizontal displacements of triangulation points in the Tango district $(1927-1884 \sim 1889)$.

\begin{tabular}{|c|c|c|c|c|c|}
\hline \multirow{2}{*}{ No. } & \multirow{2}{*}{ Station } & \multicolumn{2}{|c|}{ Displacement (m) } & \multicolumn{2}{|c|}{ Position $(H=10 \mathrm{~km})$} \\
\hline & & $U_{X}$ & $U_{Y}$ & $X / H$ & $Y / H$ \\
\hline 1 & Setoyama & -0.45 & 0.43 & 1.030 & 0.115 \\
\hline 2 & Hamagasira & -0.33 & 0.25 & 1.425 & 0.020 \\
\hline 3 & Yosidu & -0.55 & 0.43 & 0.530 & 0.130 \\
\hline 4 & Dogatani & -0.50 & 0.46 & 1.190 & 0.410 \\
\hline 5 & Kurosaki & -0.56 & 0.49 & 1.285 & 0.680 \\
\hline 6 & Minamitani & -0.58 & 0.52 & 0.555 & 0.540 \\
\hline 7 & Nisitani & -0.50 & 0.56 & 0.840 & 0.760 \\
\hline 8 & Yasuke & -0.60 & 0.43 & 1.070 & 1.030 \\
\hline 9 & Sengokuyama & -0.58 & 0.37 & 1.220 & 1.360 \\
\hline 10 & Tsudumigatake & -0.52 & 0.52 & 0.635 & 0.850 \\
\hline 11 & Tsunoduki & -0.50 & 0.31 & 0.945 & 1.485 \\
\hline 12 & Moriage & -0.50 & 0.43 & 1.070 & 1.750 \\
\hline 13 & Miemura & 0.12 & 0.92 & 0.150 & 0.275 \\
\hline 14 & Mititani & -0.48 & 0.68 & 0.320 & 0.600 \\
\hline 15 & Yanaganaru & -0.60 & 0.56 & 0.600 & 1.045 \\
\hline 16 & Dake & -0.60 & 0.46 & 0.705 & 1.320 \\
\hline 17 & Inunegasira & -0.63 & 0.43 & 0.685 & 1.555 \\
\hline 18 & Taikoyama & -0.47 & 0.34 & 0.840 & 1.835 \\
\hline 19 & Kasayama & -0.48 & 0.40 & 0.800 & 2.140 \\
\hline 20 & Takao & -0.73 & 0.65 & 0.365 & 1.130 \\
\hline 21 & Kongosan & -0.60 & 0.68 & 0.280 & 1.435 \\
\hline 22 & Gamatani & -0.75 & 0.49 & 0.400 & 1.570 \\
\hline 23 & Kubo & -0.68 & 0.43 & 0.550 & 1.960 \\
\hline 24 & Nimatu & -0.55 & 0.43 & 0.610 & 2.265 \\
\hline 25 & Kidumiyama & -0.55 & 0.80 & 0.070 & 0.760 \\
\hline 26 & Mitinoku & -0.96 & 0.80 & 0.020 & 1.865 \\
\hline 27 & Ooisi & -0.91 & 0.59 & 0.270 & 1.970 \\
\hline 28 & Itigao & -0.87 & 0.63 & 0.245 & 2.260 \\
\hline 29 & $\mathrm{He}$ & -0.75 & 0.62 & 0.410 & 2.405 \\
\hline 30 & Misakayama & -0.43 & 0.89 & -0.020 & 0.420 \\
\hline 31 & Yosizawa & -0.75 & 0.80 & -0.045 & 1.130 \\
\hline 32 & Naya & -0.88 & 0.83 & -0.120 & 1.510 \\
\hline 33 & Ootani & -0.98 & 0.92 & -0.265 & 1.810 \\
\hline 34 & Oohira & -0.96 & 0.71 & -0.165 & 2.175 \\
\hline 35 & Takase & -0.76 & 0.96 & -0.200 & 0.800 \\
\hline 36 & Yada & -0.93 & 1.08 & -0.325 & 1.310 \\
\hline 37 & Mineyama & -0.91 & 1.23 & $-0,420$ & 0.965 \\
\hline 38 & Akasaka & -0.88 & 0.83 & -0.570 & 1.125 \\
\hline 39 & Asago & -1.26 & 1.05 & -0.570 & 1.490 \\
\hline 40 & Obama & -0.55 & 1.17 & -0.675 & 1.885 \\
\hline 41 & Kaitanidake & 0.05 & 0.06 & -0.155 & 0.205 \\
\hline 42 & Ainome & 0.03 & -0.99 & -0.660 & 0.820 \\
\hline 43 & Nisiyama & -0.10 & -1.36 & -0.805 & 1.030 \\
\hline 44 & Arai & -0.03 & -1.23 & -0.930 & 1.240 \\
\hline
\end{tabular}


Table 2.1. (continued)

\begin{tabular}{|c|c|c|c|c|c|}
\hline \multirow{2}{*}{ No. } & \multirow{2}{*}{ Station } & \multicolumn{2}{|c|}{ Displacement (m) } & \multicolumn{2}{|c|}{ Position $(H=10 \mathrm{~km})$} \\
\hline & & $U_{X}$ & $U_{Y}$ & $X / H$ & $Y / H$ \\
\hline 45 & Simooka & 0.53 & -1.13 & -0.945 & 1.600 \\
\hline 46 & Tukinami & 0.03 & -1.20 & -1.175 & 1.520 \\
\hline 47 & Byobuyama & -0.10 & -0.56 & -0.420 & 0.495 \\
\hline 48 & Kidu & -0.10 & -1.05 & -1.160 & 1.125 \\
\hline 49 & Mizono & -0.08 & -0.86 & -1.405 & 1.185 \\
\hline 50 & Hiziyama & 0.00 & -0.89 & -0.935 & 0.680 \\
\hline 51 & Nyoo & -0.07 & -0.81 & -1.230 & 0.845 \\
\hline 52 & Yakedosi & 0.08 & -0.71 & -0.790 & 0.440 \\
\hline 53 & Sano & 0.13 & -0.68 & -1.075 & 0.555 \\
\hline 54 & Nonaka & 0.10 & -0.56 & -1.400 & 0.610 \\
\hline 55 & Isanagosan & 0.02 & -0.48 & -0.655 & 0.200 \\
\hline 56 & Kaya & 0.05 & -0.52 & -1.000 & 0.305 \\
\hline 57 & Hutamata & 0.00 & -0.43 & -1.160 & 0.240 \\
\hline 58 & Itinono & 0.18 & -0.43 & -1.420 & 0.225 \\
\hline 59 & Nakahudi & -0.23 & -0.34 & -0.895 & -0.040 \\
\hline 60 & Simomura & 0.02 & -0.18 & -1.260 & -0.080 \\
\hline 61 & Oogatani & -0.40 & 0.25 & -0.270 & -0.090 \\
\hline 62 & Iwaya & -0.18 & -0.19 & -0.605 & -0.145 \\
\hline 63 & Nanmeizan & 0.00 & -0.19 & -1.155 & -0.270 \\
\hline 64 & Okuhudi & -0.15 & -0.15 & -0.780 & -0.375 \\
\hline 65 & Kayaoku & -0.15 & -0.01 & -0.550 & -0.430 \\
\hline 66 & Akahanamura & -0.08 & 0.00 & -0.960 & -0.615 \\
\hline 67 & Arikuma & -0.25 & 0.19 & -0.300 & -0.460 \\
\hline 68 & Egasayama & -0.10 & 0.09 & -0.545 & -0.885 \\
\hline 69 & Dannosaka & -0.20 & 0.00 & -0.300 & -0.760 \\
\hline 70 & Akaisidake & -0.13 & 0.25 & -0.225 & -0.950 \\
\hline 71 & Kanase & -0.20 & 0.28 & -0.060 & -0.470 \\
\hline 72 & Sendyogatake & -0.18 & 0.25 & -0.035 & -0.855 \\
\hline 73 & Ooeyama & -0.25 & 0.34 & 0.125 & -0.675 \\
\hline 74 & Tyuda & -0.25 & 0.31 & 0.245 & -0.470 \\
\hline 75 & Sorayama & -0.08 & 0.43 & 0.440 & -0.855 \\
\hline 76 & Toisigatake & -0.13 & 0.37 & 0.750 & -0.910 \\
\hline 77 & Hukotoge & -0.20 & 0.43 & 0.525 & -0.575 \\
\hline 78 & Isikawamura & -0.41 & 0.43 & 0.380 & -0.225 \\
\hline 79 & Odamura & -0.28 & 0.46 & 0.610 & -0.365 \\
\hline 80 & Seihozi & -0.30 & 0.31 & 0.870 & -0.730 \\
\hline 81 & Dinusi & -0.35 & 0.28 & 1.085 & -0.580 \\
\hline 82 & Okuyama & -0.40 & 0.37 & 0.910 & -0.195 \\
\hline 83 & Yuragatake & -0.39 & 0.30 & 1.320 & -0.225 \\
\hline 84 & Kanawaridani & -0.50 & 0.46 & 0.505 & -0.060 \\
\hline 85 & Waki & -0.43 & 0.31 & 1.230 & -0.085 \\
\hline
\end{tabular}

Origin of the $X-Y$ coordinates; Oidi $\left(35.53^{\circ} \mathrm{N}, 135.11^{\circ} \mathrm{E}\right)$.

No,; corresponds to Fig. 1. 
Table 2.2. Vertical displacements of bench marks along E-W levelling route from Kumihama to Maizuru (1927-1888).

\begin{tabular}{|c|c|c|c|}
\hline \multirow{2}{*}{ No. of bench mark } & \multirow{2}{*}{ Displacement (m) } & \multicolumn{2}{|c|}{ Position $(H=10 \mathrm{~km})$} \\
\hline & & $X / H$ & $Y / H$ \\
\hline 1222 & 0.01 & -1.310 & 0.570 \\
\hline 1223 & 0.04 & -1.130 & 0.495 \\
\hline 1224 & 0.09 & -1.000 & 0.510 \\
\hline 1225 & 0.12 & -0.905 & 0.520 \\
\hline 1226 & 0.19 & -0.710 & 0.565 \\
\hline 1227 & 0.23 & -0.615 & 0.720 \\
\hline 1228 & 0.40 & -0.540 & 0.875 \\
\hline 1229 & -0.35 & -0.475 & 1.045 \\
\hline 1230 & -0.16 & -0.415 & 0.905 \\
\hline 1231 & 0.01 & -0.250 & 0.735 \\
\hline 1232 & 0.09 & -0.170 & 0.590 \\
\hline 1233 & 0.35 & -0.125 & 0.365 \\
\hline 1234 & 0.56 & 0.015 & 0.300 \\
\hline 1235 & 0.88 & 0.005 & 0.110 \\
\hline 1236 & -0.26 & 0.140 & 0.155 \\
\hline 1237 & -0.19 & 0.355 & 0.240 \\
\hline 1238 & -0.12 & 0.485 & 0.300 \\
\hline 1239 & -0.04 & 0.630 & 0.325 \\
\hline 1240 & -0.04 & 0.720 & 0.160 \\
\hline 1241 & -0.06 & 0.740 & 0.010 \\
\hline 1376 & -0.07 & 0.890 & 0.130 \\
\hline 1375 & -0.02 & 1.000 & 0.205 \\
\hline 1374 & -0.03 & 1.180 & 0.085 \\
\hline 1373 & -0.01 & 1.315 & 0.045 \\
\hline 1372 & -0.03 & 1.470 & -0.065 \\
\hline
\end{tabular}

Origin of the $X-Y$ coordinates; Oidi $\left(35.53^{\circ} \mathrm{N}, 135.11^{\circ} \mathrm{E}\right)$.

No.; corresponds to Fig. 1.

which corresponds to the number in Fig. 1 is listed in Table 2.1 (horizontal displacement) or 2.2 (vertical displacement). The origin of the coordinates is fixed to the triangulation point, Oidi $\left(35.53^{\circ} \mathrm{N}, 135.11^{\circ} \mathrm{E}\right)$, located in the center of the Tango district. The $X$-and $Y$-axis are taken parallel to the eastand north-direction respectively.

\section{Optimizing Process and Resulting Solutions}

In the previous paper (Part I), the method of geodetic data inversion has been formulated mathematically. Following the definitions in Part I, we reproduce three quantities, "resolution" of the model parameter, "expected error" of the estimated value and "effective data number" in the estimation, as the measures of the reliability of the resulting solution. 
Consider a $n \times m$ linear system which is already standardized by "predicted errors" of the data and "maximum allowable deviations" of the model parameters,

$$
\Delta y_{i}=\sum_{j=1}^{m} A_{i j} \Delta x_{j} \quad(i=1, \ldots, n)
$$

where $A_{i j}$ is the $i j$ element of a known coefficient matrix $A$, and $\Delta y_{i}$ and $\Delta x_{j}$ are the correction term of the data and that of an unknown model parameter respectively. Defining the matrix elements, $U_{i k}, V_{j k}$ and $\lambda_{l k}$, by the following equations (decomposition theorem for an arbitrary $n \times m$ matrix; refer to section 2.3 in Part I),

$$
A_{i j}=\sum_{k=1}^{q} U_{i k} V_{j k} / \lambda_{k} \quad\left(\lambda_{k} ; \text { positive eigenvalue }\right),
$$

the resolution $r_{j}$, expected error $s_{j}$ and effective data number $N_{j}$ are written as

$$
\begin{aligned}
r_{j}^{2} & =\sum_{k=1}^{m}\left(\sum_{l=1}^{q} V_{j l} V_{k l}-\delta_{j k}\right)^{2} \quad(j=1, \ldots, m), \\
s_{j}^{2} & =\sum_{k=1}^{q}\left(V_{j k} / \lambda_{k}\right)^{2} \quad(j=1, \ldots, m), \\
N_{j} & =\left(1-r_{j}\right) \sum_{i=1}^{n} e_{j i} / e_{j \max } \quad(j=1, \ldots, m),
\end{aligned}
$$

with

$$
e_{j i}=\left|\sum_{k=1}^{q} V_{j k} U_{i k}\right| \lambda_{k} \mid \quad(j=1, \ldots, m, i=1, \ldots, n),
$$

where $\delta_{j l k}, e_{j \max }$ and $q$ are the Kronecker's symbol, maximum value of $e_{j i}$ $(i=1, \ldots, n)$ and "effective number" of the degree of freedom in the data respectively. It is noted that the effective data number $N_{j}$ is an indicator of how many data contribute effectively to determining the $j$-th model parameter.

To interpret the observed deformation fields, we take a multiple-fault system composed of several dimensional faults in an elastic half-space, e.g.; two-fault model in 3.1, which consists of two independent rectangular faults, and six-fault model in 3.2, where the model consists of two complex-faults, and each of them is composed of three rectangular faults jointed to each other at the fault corners. In either case, the predicted errors of data $\sigma_{i}$ are defined as

$$
\sigma_{i}=\sigma_{0}\left|o_{\max }\right|\left(1+\left|o_{i}\right| o_{\max } \mid\right) / 2 \quad(i=1, \ldots, n),
$$

where $\sigma_{0}$ is called the "error coefficient", and $o_{\max }$ is the maximum displacement of the observed data $o_{i}(i=1, \ldots, n)$. Formally, the error coefficient is guessed both from the effect of deficiencies in the model and from the accuracy of observed data. However, as discussed in section 2.4 of Part $I$, in practice the appropriate value of $\sigma_{0}$ should be determined through the analysis of real data, because we have no reliable information about the effect of deficiencies in the model. 


\subsection{Two-fault model}

The two-fault model (Fig. 3) is uniquely prescribed by 18 independent model parameters $(2 \times 9$ fault parameters). As the fault parameters, we take the following quantities; the dip-angle $(\delta)$, slip direction $(\lambda)$, magnitude of dislocation $(D)$, width $(W)$, depth of upper fault edge $(d)$ and the location of the upper-left and -right corners of the fault plane $\left(a_{0}, b_{0} ; a_{1}, b_{1}\right)$, where the slip direction is measured counterclockwise from horizon on the fault plane. As to "presupposed conditions" for analysis, the initial fault model is already given in Table 1, and others, i.e. the error coefficient and the maximum allowable deviations, are presented in Table 3, where the capital letters, $G$ and $Y$, denote the Gomura and the Yamada fault respectively. It is noted that the maximum allowable deviations are determined apriori only from our demand for certainty in the model, but in the present analyzing method the resulting solutions are not significantly affected by some variations in these values.

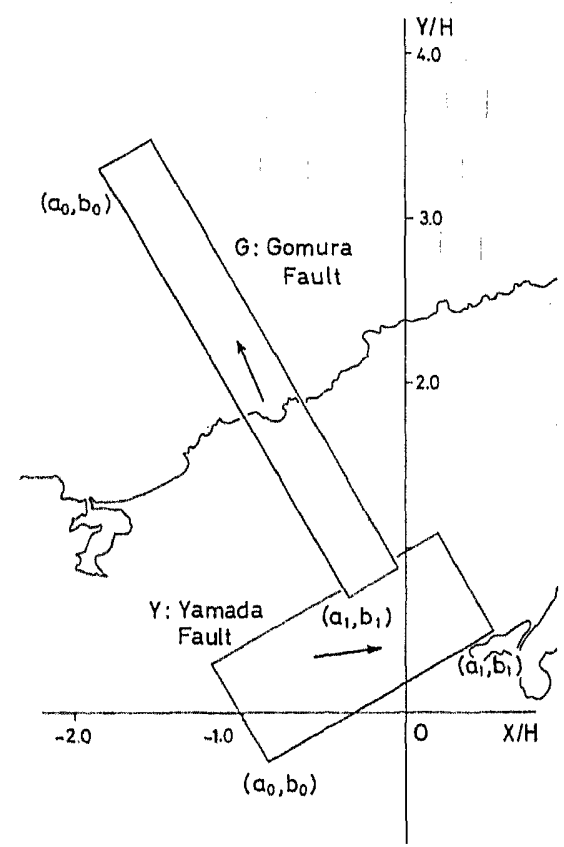

Fig. 3. Geometry of two-fault model. The rectangles indicate the projection of the starting fault model on the $X-Y$ plane, where the unit of length $(H)$ is $10 \mathrm{~km}$.

Table 3. Presupposed conditions for analysis (Two-fault model).

\begin{tabular}{|c|c|c|c|c|c|c|c|c|c|c|}
\hline & & $\tilde{o}$ & $\lambda$ & $D(\mathrm{~m})$ & $W(\mathrm{~km})$ & $d(\mathrm{~km})$ & $a_{0}$ & $b_{0}$ & $a_{1}$ & $b_{1}$ \\
\hline & $\mathrm{G}$ & $5.0^{\circ}$ & $5.0^{\circ}$ & 0.20 & 3.0 & 0.10 & 0.20 & 0.20 & 0.05 & 0.05 \\
\hline$t_{j}$ & $Y$ & $5.0^{\circ}$ & $5.0^{\circ}$ & 0.20 & 3.0 & 0.10 & 0.10 & 0.10 & 0.10 & 0.10 \\
\hline
\end{tabular}

Error coefficient; $\sigma_{0}=0.15$

$t_{j}$; maximum allowable deviations. 


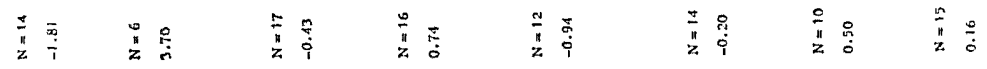

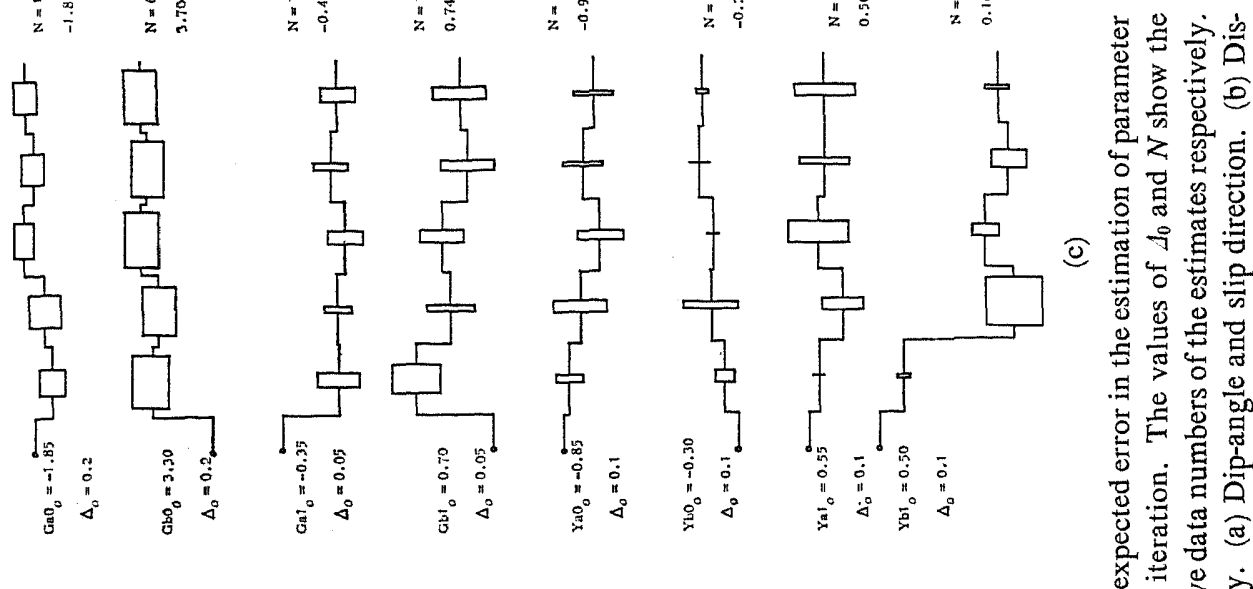

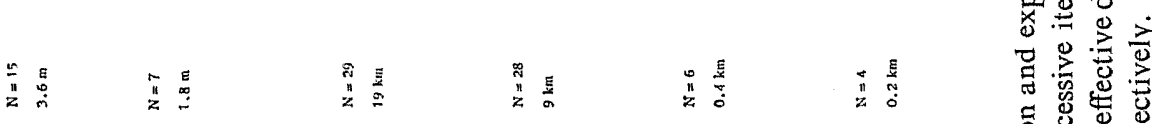

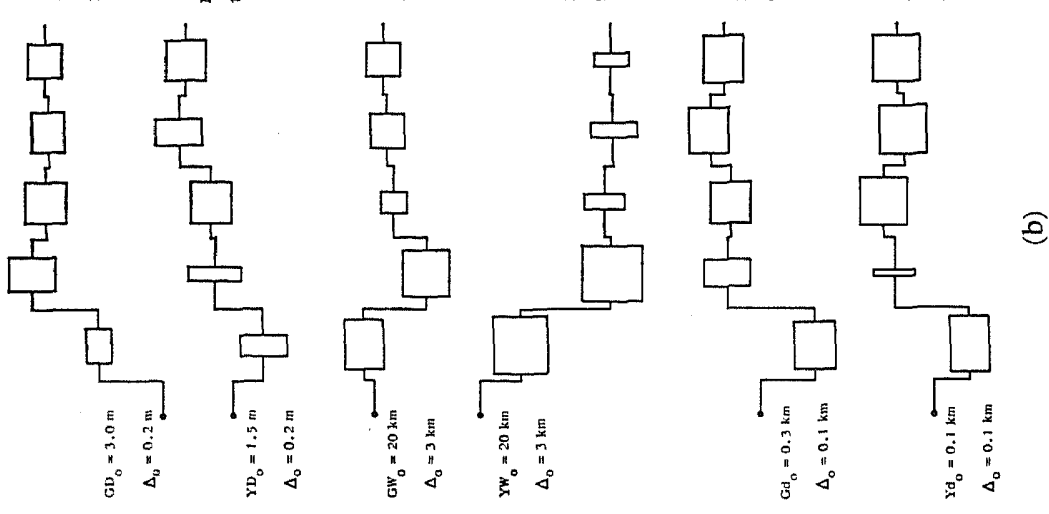

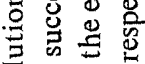

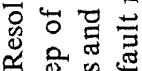

눙

迎苋

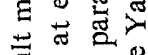

$5 \frac{0}{2}$

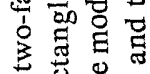

苋造

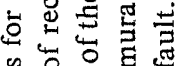

离吉言员出

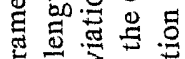

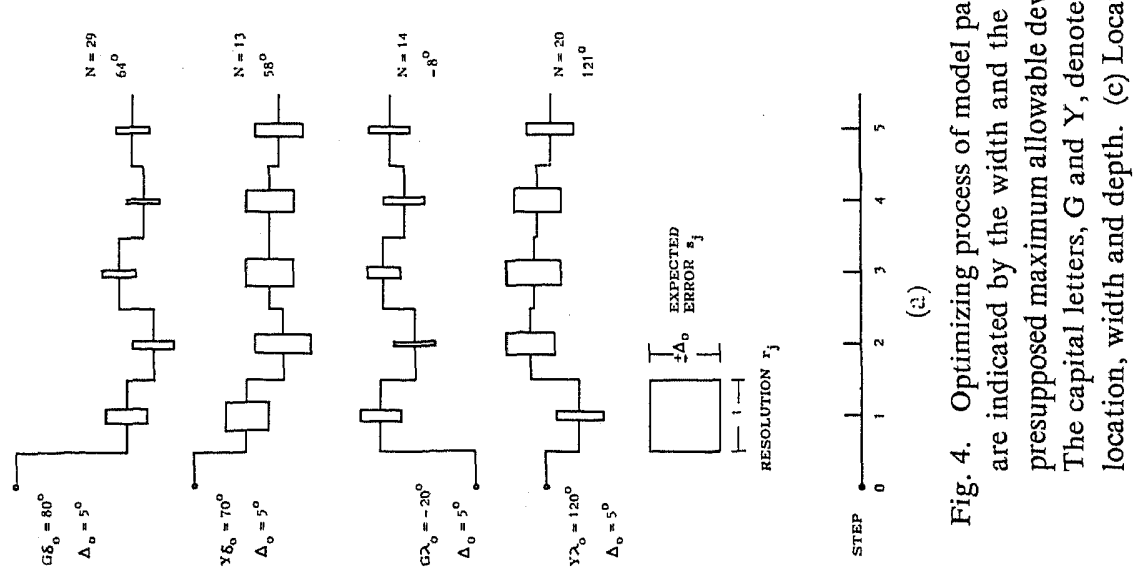


Through a successive iteration of inversions, the model parameters are simultaneously optimized step by step as shown in Fig. 4. At each step of the iteration, the resolution $r_{j}$ and expected error $s_{j}$ in the estimation are indicated by the width and the length of the rectangle respectively. If $r_{j}$ is small enough, information from the data is distinctly reflected in the estimation of the $j$-th parameter. Conversely, if $r_{j}$ is nearly equal to 1 , we can only obtain a meaningless conclusion that the $j$-th parameter is indefinite under such presupposed conditions. When the estimate is accompanied by large values both in the resolution and expected error, it can be said that the observed data contain little information on its parameter.

The effective data number $N_{j}$ indicates the number of data which contribute effectively to determining the $j$-th model parameter. If $N_{j}$ is large enough, the estimate is reliable. When the effective data number is not so large, the estimate is not reliable, because the resulting solution may be remarkably changed by adding a new effective datum to the previous data set. In the present case (two-fault model), it is noticed from Fig. 4 that the estimation with a high degree of reliability (large $N_{j}$ ) is always accompanied with a good resolution ( $\operatorname{small} r_{j}$ ). Such a relation between $N_{j}$ and $r_{j}$ holds, if and only if the system is strongly over-constrained (refer to 3.2 ).

The optimal fault parameters obtained from the analysis of triangulation data are listed in Table 4. For the Gomura fault, the slip motion is predominantly left-lateral $\left(\lambda=-8^{\circ}\right)$ along a plane dipping eastward with an angle of $64^{\circ}$. This fault extends out into the Sea of Japan in the direction of $N 26^{\circ} \mathrm{W}$, but its location at the northwestern end is indefinite, because of the lack of data. The average dislocation is $3.7 \mathrm{~m}$ on the fault plane with dimensions of about $33 \mathrm{~km}$ (length) $\times 19 \mathrm{~km}$ (width). For the Yamada fault, the dip-angle and the slip direction are estimated to be $58^{\circ} \mathrm{N}$ and $120^{\circ}$ respectively, that is, the slip motion is a right-lateral reverse type. This result almost agrees with that by Walsh (1969). Contrary to the expectation from visible cracks, this fault stretches from the base of the Tango peninsula to the west $\left(\mathrm{N} 103^{\circ} \mathrm{W}\right.$ ) with dimensions of $15 \mathrm{~km} \times 9 \mathrm{~km}$. The average dislocation is about $1.8 \mathrm{~m}$. The principal axes of compression calculated respectively by these two fault models almost agree (MATSU'URA et al., 1976).

From these results, we can obtain some conclusions as follows: i) the extension of two main faultings almost coincides with the region accompanied

Table 4. Optimal solution (Two-fault model).

\begin{tabular}{rrrrrrrrrrr} 
& & $\delta$ & $\lambda$ & $D(\mathrm{~m})$ & $W(\mathrm{~km})$ & $d(\mathrm{~km})$ & \multicolumn{1}{c}{$a_{0}$} & \multicolumn{1}{c}{$b_{0}$} & \multicolumn{1}{c}{$a_{1}$} & $b_{1}$ \\
\hline \multirow{2}{*}{$\hat{x}_{j}$} & $\mathrm{G}$ & $64^{\circ} \mathrm{E}$ & $-8^{\circ}$ & 3.70 & 19.0 & 0.40 & -1.82 & 3.71 & -0.43 & 0.74 \\
& $\mathrm{Y}$ & $58^{\circ} \mathrm{N}$ & $120^{\circ}$ & 1.80 & 9.0 & 0.20 & -0.94 & -0.21 & 0.50 & 0.16 \\
\hline
\end{tabular}

$\hat{\boldsymbol{x}}_{j}$; optimal model parameters. 


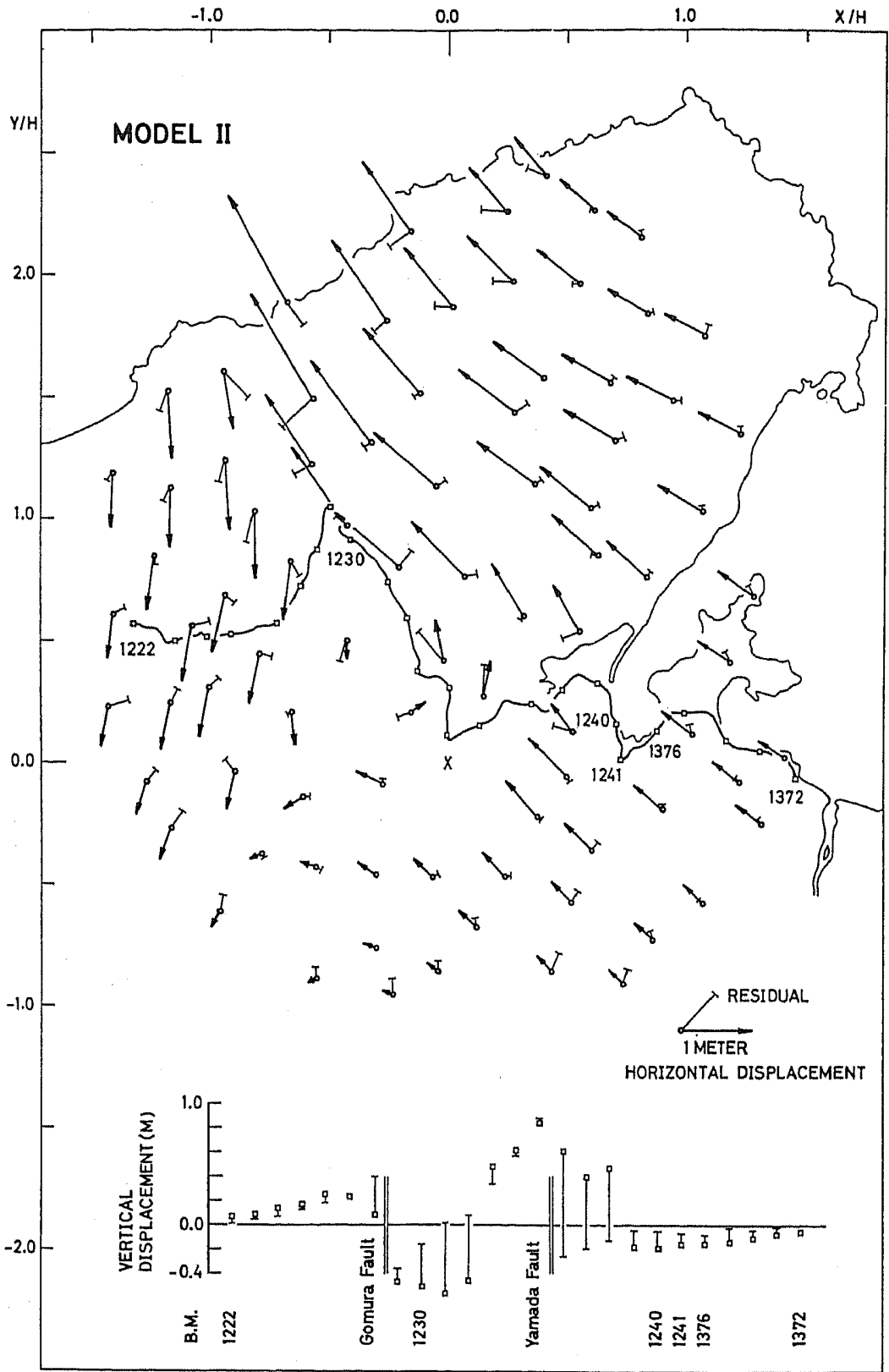

Fig. 5. Horizontal and vertical displacements calculated by Model II (optimal twofault model). The residuals are given by the error vectors for triangulation data and the error bars for levelling data respectively. 
with the occurrence of aftershocks, and ii) these seismic faults constitute a system of conjugate faults caused by a single stress system of NW-SE compression.

Theoretical displacements calculated by the optimal two-fault model (referred to as Model II) are shown in Fig. 5 with the residual errors. The Model II fits well to the observed triangulation data, except to those at the southwestern area of the Gomura fault, where the deformation fields seem to be disturbed by the effect of faulting due to the Tazima earthquake in 1925 . The goodness of fit of the optimal model to the observations is represented by a weighted mean error, which is defined by $\sigma_{e}=\sqrt{\frac{1}{n} \sum_{i=1}^{n}\left(o_{i}-\hat{y}_{i}\right)^{2} / \sigma_{i}^{2}}$, where $\hat{y}_{i}(i=1, \ldots, n)$ are the theoretical data. For the Model II, the value of $\sigma_{e}$ is 0.7 and satisfys the inequality for the appropriateness in the selection of $\sigma_{e}$, $1 / 2<\sigma_{a}<1$. This shows that the presupposed error coefficient $(0.15)$ is appropriate.

For the levelling data, which are not used in the present analysis, we cannot obtain satisfactory interpretation by the two-fault model (Fig. 5). The discrepancies between the observed and the theoretical data are remarkable at the bench marks close to the faults. This indicates that the deformation fields should be modelled by a more complex fault system to interpret both the triangulation and the levelling data, because the variation in the strike along each seismic fault cannot be represented by a simple rectangular fault (twofault model).

\subsection{Six-fault model}

Producing a new data set by adding 25 levelling data (Table 2.2) to the previous set of triangulation data, more detailed analysis is carried out for the two seismic faults. Consider a six-fault model as shown in Fig. 6 to take account of the variation in the strike along the faults, where each complexfault consists of three rectangular faults jointed to each other at the fault corners. This model is prescribed by a set of 46 independent model parameters produced from $6 \times 9$ fault parameters with 8 restrictions among them.

The initial values of model parameters are determined from the results obtained in 3.1. These values are presented in Table 5, with other presupposed conditions, where the capital letters, $G_{1}, G_{2}, G_{3}, Y_{1}, Y_{2}$ and $Y_{3}$, denote the corresponding elemental faults (refer to Fig. 6) respectively. For the present model, the error coefficient is set up apriori as 0.10 , because the degree of deficiencies in the six-fault model should be lower than that in the two-fault model. As to the maximum allowable deviations, it is not necessary to pay a great deal of attention to selecting the appropriate values, since the method of geodetic data inversion includes a process of re-standardization of the model parameters. 


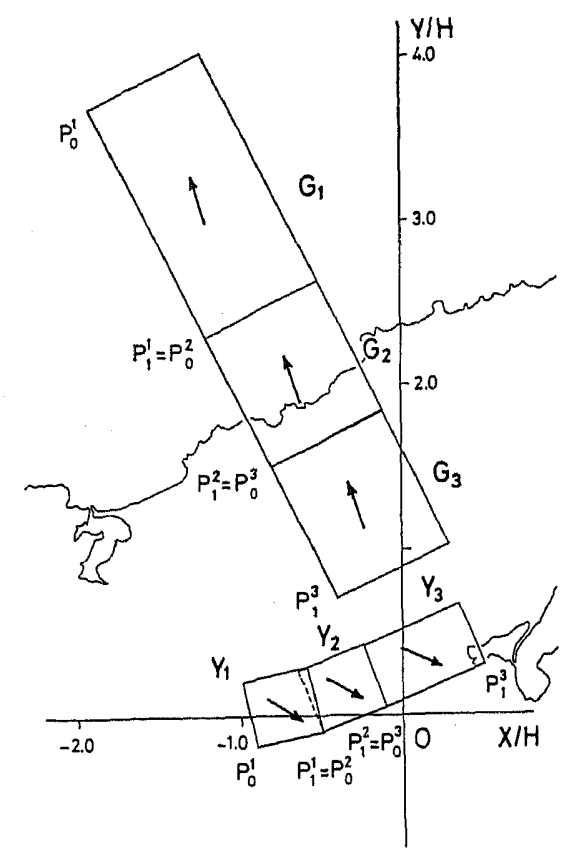

Fig. 6. Geometry of six-fault model. The rectangles indicate the projection of the starting fault model on the $X-Y$ plane, where the unit of length $(H)$ is $10 \mathrm{~km}$. The capital letters, $G_{1}, G_{2}, G_{3}, Y_{1}, Y_{2}$ and $\mathrm{Y}_{3}$ denote the corresponding elemental fault respectively.

Table 5. Presupposed conditions for analysis (Six-fault model).

\begin{tabular}{|c|c|c|c|c|c|c|c|c|c|c|}
\hline & & $\delta$ & $\lambda$ & $D(\mathrm{~m})$ & $W(\mathrm{~km})$ & $d(\mathrm{~km})$ & $a_{0}$ & $b_{0}$ & $a_{1}$ & $b_{1}$ \\
\hline \multirow{6}{*}{$x^{0}$} & $\mathrm{G}_{1}$ & $65^{\circ} \mathrm{E}$ & $-10^{\circ}$ & 3.60 & 18.0 & 0.40 & -1.90 & 3.70 & -1.20 & 2.30 \\
\hline & $\mathrm{G}_{2}$ & $65^{\circ} \mathrm{E}$ & $-10^{\circ}$ & 3.60 & 18.0 & 0.40 & -1.20 & 2.30 & 0.80 & 1.50 \\
\hline & $\mathrm{G}_{3}$ & $65^{\circ} \mathrm{E}$ & $-10^{\circ}$ & 3.60 & 18.0 & 0.40 & -0.80 & 1.50 & -0.40 & 0.70 \\
\hline & $Y_{1}$ & $60^{\circ} \mathrm{N}$ & $120^{\circ}$ & 1.80 & 8.0 & 0.20 & -0.90 & -0.20 & -0.50 & 0.10 \\
\hline & $Y_{2}$ & $60^{\circ} \mathrm{N}$ & $120^{\circ}$ & 1.80 & 8.0 & 0.20 & -0.50 & -0.10 & -0.10 & 0.05 \\
\hline & $Y_{3}$ & $60^{\circ} \mathrm{N}$ & $120^{\circ}$ & 1.80 & 8.0 & 0.20 & -0.10 & 0.05 & 0.50 & 0.30 \\
\hline \multirow{6}{*}{$t_{j}$} & $\mathrm{G}_{1}$ & $3.0^{\circ}$ & $3.0^{\circ}$ & 0.20 & 2.0 & 0.10 & 0.20 & 0.20 & 0.10 & 0.1 \\
\hline & $\mathrm{G}_{2}$ & $3.0^{\circ}$ & $3.0^{\circ}$ & 0.20 & 2.0 & 0.10 & 0.10 & 0.10 & 0.05 & 0.0 \\
\hline & $\mathrm{G}_{3}$ & $3.0^{\circ}$ & $3.0^{\circ}$ & 0.20 & 2.0 & 0.10 & 0.05 & 0.05 & 0.05 & 0.0 \\
\hline & $Y_{1}$ & $3.0^{\circ}$ & $3.0^{\circ}$ & 0.10 & 1.0 & 0.10 & 0.10 & 0.10 & 0.05 & 0.0 \\
\hline & $Y_{2}$ & $3.0^{\circ}$ & $3.0^{\circ}$ & 0.10 & 1.0 & 0.10 & 0.05 & 0.05 & 0.05 & 0.0 \\
\hline & $Y_{3}$ & $3.0^{\circ}$ & $3.0^{\circ}$ & 0.10 & 1.0 & 0.10 & 0.05 & 0.05 & 0.10 & \\
\hline
\end{tabular}

Error coefficient; $\sigma_{0}=0.10$

$x_{j}^{0}$; initial value of model parameters.

$t_{j}$; maximum allowable deviations.

The optimizing process of the model parameters is completed, in the present computation, at the ninth step of the successive iteration of inversions. The final estimates are given in Table 6 , with the corresponding resolutions $r_{j}$, expected errors $s_{j}$ and effective data numbers $N_{j}$. The system is not strongly over-constrained, unlike that in the case of the two-fault model. It should be 
Table 6. Optimal solution (Six-fault model).

\begin{tabular}{|c|c|c|c|c|c|c|c|c|c|c|}
\hline & & i) & $\lambda$ & $D$ & $W$ & $d$ & $a_{0}$ & $b_{0}$ & $a_{1}$ & $b_{1}$ \\
\hline \multirow{6}{*}{$\hat{x}_{j}$} & $\mathrm{G}_{1}$ & $72^{\circ} \mathrm{E}$ & $-3^{0}$ & $4.1 \mathrm{~m}$ & $25 \mathrm{~km}$ & $0.3 \mathrm{~km}$ & -1.65 & 4.82 & -1.02 & 2.12 \\
\hline & $\mathrm{G}_{2}$ & $76^{\circ} \mathrm{E}$ & $-16^{\circ}$ & 3.1 & 22 & 0.3 & -1.02 & 2.12 & -0.88 & 1.64 \\
\hline & $G_{3}$ & $90^{\circ} \mathrm{V}$ & -14 & 4.2 & 2 & 0.3 & -0.88 & 1.64 & -0.20 & 0.37 \\
\hline & $Y_{1}$ & $54^{\circ} \mathrm{N}$ & $118^{\circ}$ & 1.9 & 6 & 0.1 & -0.88 & -0.05 & -0.58 & -0.13 \\
\hline & $Y_{2}$ & $51^{\circ} \mathrm{N}$ & 122 & 2.1 & 9 & 0.1 & -0.58 & -0.13 & -0.12 & 0.05 \\
\hline & $Y_{3}$ & $66^{\circ} \mathrm{N}$ & $111^{\circ}$ & 2.2 & 11 & 0.1 & -0.12 & 0.05 & 0.18 & 0.19 \\
\hline \multirow{6}{*}{$s_{j}$} & $\mathrm{G}_{1}$ & $1.2^{\circ}$ & $0.8^{\prime \prime}$ & $0.07 \mathrm{~m}$ & $0.6 \mathrm{~km}$ & $0.05 \mathrm{~km}$ & 0.08 & 0.05 & 0.03 & 0.03 \\
\hline & $G_{2}$ & $0.5^{\prime \prime}$ & $0.6^{\circ}$ & 0.07 & 0.3 & 0.05 & 0.03 & 0.03 & 0.02 & 0.02 \\
\hline & $\mathrm{G}_{3}$ & $2.3^{\circ}$ & $1.6^{\circ}$ & 0.05 & 0.2 & 0.05 & 0.02 & 0.02 & 0.01 & 0.02 \\
\hline & $Y_{1}$ & $0.9^{\circ}$ & $0.8^{\circ}$ & 0.03 & 0.4 & 0.05 & 0.02 & 0.03 & 0.04 & 0.01 \\
\hline & $Y_{2}$ & $1.3^{\circ}$ & $1.7^{\prime \prime}$ & 0.04 & 0.6 & 0.05 & 0.04 & 0.01 & 0.02 & 0.01 \\
\hline & $Y_{3}$ & $1.1^{\circ}$ & $1.2^{\prime \prime}$ & 0.02 & 0.3 & 0.05 & 0.02 & 0.01 & 0.03 & 0.02 \\
\hline \multirow{6}{*}{$r_{j}$} & $G_{1}$ & 0.82 & 0.95 & 0.75 & 0.90 & 0.37 & 0.26 & 0.87 & 0.32 & 0.92 \\
\hline & $\mathrm{G}_{2}$ & 0.98 & 0.97 & 0.88 & 0.99 & 0.37 & 0.32 & 0.92 & 0.33 & 0.63 \\
\hline & $G_{3}$ & 0.64 & 0.14 & 0.94 & 0.06 & 0.37 & 0.33 & 0.63 & 0.15 & 0.16 \\
\hline & $Y_{1}$ & 0.95 & 0.96 & 0.98 & 0.88 & 0.20 & 0.06 & 0.09 & 0.42 & 0.08 \\
\hline & $Y_{2}$ & 0.80 & 0.79 & 0.93 & 0.67 & 0.20 & 0.42 & 0.08 & 0.80 & 0.37 \\
\hline & $Y_{3}$ & 0.87 & 0.90 & 0.97 & 0.95 & 0.20 & 0.80 & 0.37 & 0.15 & 0.08 \\
\hline \multirow{6}{*}{$N_{j}$} & $G_{1}$ & 5 & 2 & 9 & 4 & 12 & 30 & 5 & 9 & 2 \\
\hline & $G_{2}$ & 1 & 1 & 2 & 1 & 12 & 9 & 2 & 15 & 12 \\
\hline & $\mathrm{G}_{3}$ & 2 & 10 & 2 & 11 & 12 & 15 & 12 & 8 & 9 \\
\hline & $Y_{1}$ & 10 & 14 & 6 & 13 & 10 & 6 & 1 & 1 & 1 \\
\hline & $Y_{2}$ & 22 & 17 & 1 & 17 & 10 & 1 & 1 & 18 & 18 \\
\hline & $Y_{:}$ & 5 & 4 & 2 & 6 & 10 & 18 & 18 & 13 & 12 \\
\hline
\end{tabular}

$\hat{x}_{j}$; optimal model parameters. $s_{j}$; expected errors. $r_{j}$; resolutions. $N_{j}$ i effective data numbers.

noted that two quantities, $r_{j}$ and $N_{j}$, are the measures of different types in the physical meaning as pointed out in 3.1. In general, the fault-plane solution can be regarded as a representation of the gross aspect of the actual complex faulting. From such a point of view, resolution $r_{j}$ is not taken as a reasonable measure of reliability, unless the system is strongly over-constrained.

As a whole, results of the present analysis are not so reliable except for several parameters, such as the dip-angles of $Y_{1}$ and $Y_{2}$, the slip directions of $G_{3}, Y_{1}$ and $Y_{2}$, the widths of $G_{3}, Y_{1}$ and $Y_{2}$, etc. (Table 6). However, it is possible to point out some interesting feature of each faulting from these results. The Gomura fault seems to consist of two types of faulting, that is a normal and predominantly left-lateral slip on a plane dipping eastward with a width of about $25 \mathrm{~km}\left(\mathrm{G}_{1}\right.$ and $\mathrm{G}_{2}$; northwestern part) and left-lateral motion along a nearly vertical plane with a width of only $2 \mathrm{~km}\left(\mathrm{G}_{9}\right.$; southeastern part). The strike also varies from $\mathrm{N} 13^{\circ} \mathrm{W}\left(\mathrm{G}_{1}\right)$ to $\mathrm{N} 28^{\circ} \mathrm{W}\left(\mathrm{G}_{3}\right)$ along the fault. For the 


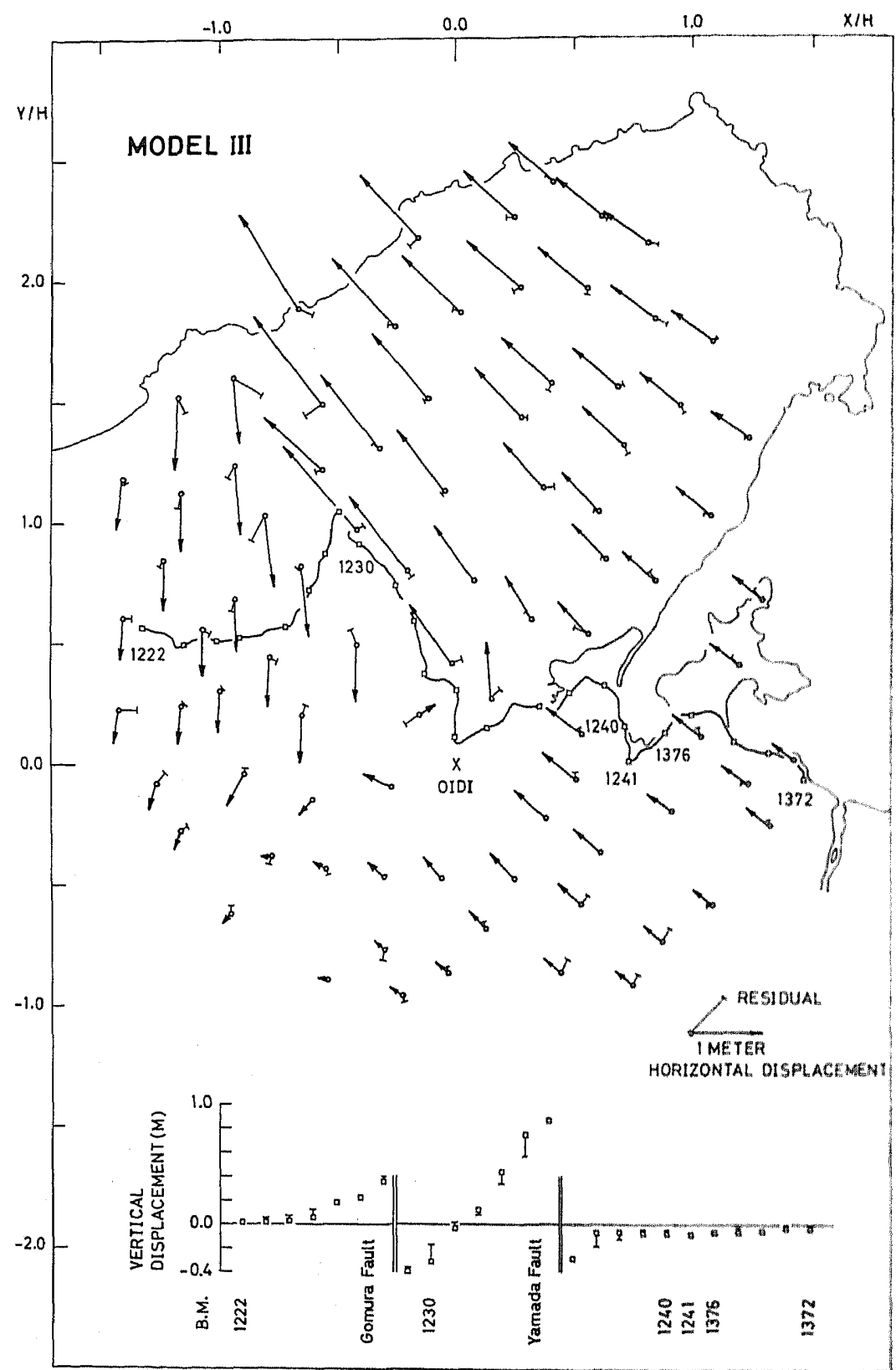

Fig. 7. Horizontal and vertical displacements calculated by Model Irr (optimal sixfault model). The residuals are given by the error vectors for triangulation data and the error bars for levelling data respectively. 
Yamada fault, a gradual increase in width is from the western part to the eastern part $\left(Y_{1} W=6 \mathrm{~km}, Y_{2} W=9 \mathrm{~km}, Y_{3} W=11 \mathrm{~km}\right)$. The strike of fault is $\mathrm{N} 103^{\circ} \mathrm{E}$ at the western part and $\mathrm{N} 64^{\circ} \mathrm{E}$ at the eastern part. The changes both in dip-angle and in slip direction are not remarkable along this faulting.

The horizontal and vertical displacements calculated by the optimal sixfault model (referred to as Model III) are shown in Fig. 7 with the residual errors. The observed deformation fields are almost completely interpreted by the Model III within the predicted errors. The weighted mean error $\sigma_{e}$ takes a value of 0.8 , and satisfies the inequality, $1 / 2<\sigma_{e}<1$, that is, the presupposed error coefficient $(0.10)$ is appropriate for the six-fault model. From this result, it can be said that the total effect of various deficiencies in the mathematical model on the surface deformation fields is less than $10 \%$ for the case of a multiple-fault system composed of several rectangular faults in an elastic half-space.

\section{Computer Program}

On the basis of the mathematical formulation given in Part $I$, a computer program for the geodetic data inversion has been developed, by which a set of optimal fault parameters of seismic and aseismic events can be obtained from observed static displacement data. In the present section, a block diagram of this program is presented with several comments for actual use.

The program consists of three parts, BLOCKs I, II and III. All information, such as observed data and presupposed conditions needed for the inversion analysis, are inputted to the first part (BLOCK I). The BLOCK II is a subroutine program for producing the coefficient matrix of a linear system, in which the theoretical displacements at data points and their partial derivatives with respect to each fault parameter are calculated for the starting model at each step of the iteration. In the last block, which is a subroutine program of general linear inversion, optimization of the model parameters is carried out at each step of iteration, through a process of factorization of the coefficient matrix into the eigenvalues and eigenvectors.

The detailed explanation of each part of program is given item by item in the following part of this section, where the number for the item corresponds to that in the block diagram.

\section{BLOCK I (READ IN INFORMATION FOR ANALYSIS)}

a-1: An arbitrary quantity, $H$ (in $\mathrm{km}$ ), is taken as a unit of length.

a-2: Read in the number of triangulation points and bench marks respectively.

a-3: Each of stations is represented as a point of the Cartesian coordinates with unit of $H$ on the earth's surface.

a-4: One of the displacement components at each station corresponds to one data parameter $o_{i}(i=1, \ldots, n)$. 
b-1: For a multiple-fault system composed of $N$ elemental faults, the number of independent model parameters is given by $m=9 N-r$, where $r$ is the number of restrictions existing among fault parameters.

b-2: Appropriate value of the error coefficient, $\sigma_{0}$, is guessed apriori from the degree of deficiencies in the model.

b-3: Selection of an adequate initial model is made by an inspection of patterns of deformation fields (MATSU'URA and SATO, 1975).

b-4: Relationships between a fault plane and others are determined by this matrix.

b-5: The maximum allowable deviations of model parameters, $t_{j}(j=1, \ldots, m)$, are determined apriori from our requirement for the accuracy of estimates.

BLOCK II (COEFFICIENT MATRIX)

1: Theoretical displacements at the data points, $\hat{y}_{i}(i=1, \ldots, n)$, are calculated for the starting model, $x^{0}=\left(x_{1}^{0}, \ldots, x_{m}^{0}\right)$, at each step of iteration.

2: Partial derivatives of displacements with respect to each fault parameter are calculated for the starting model at each step.

BLOCK III (GENERAL LINEAR INVERSION)

1: Linear system, $\Delta y_{i}=\sum_{j=1}^{m} A_{i j} \Delta x_{j}$, is constructed by using the constitution matrix (I-b-4), where $\Delta y_{i}=o_{i}-\hat{y}_{i}, \Delta x_{j}=x_{j}-x_{j}^{0}$ and $A_{i j}$ is the $i j$ element of the coefficient matrix $\boldsymbol{A}$.

2: Standardization of the linear system by $t_{j}(j=1, \ldots, m)$ and $\sigma_{i}(i=1, \ldots, n)$, where $\sigma_{i}$ is the predicted error defined by $\sigma_{0}\left|o_{\max }\right|\left(1+\left|o_{i} / o_{\max }\right|\right) / 2$.

3: Matrix $A$ is decomposed into the product of three matrices, i.e. $A=U A V^{\mathrm{t}}$, where $U$ and $V$ are semi-orthonormal matrices constituted from eigenvectors, and $A$ is a diagonal matrix with nonzero elements of positive eigenvalues $\lambda_{k}(k=1, \ldots, p)$.

4: The maximum integer which satisfies the following conditions: $n\left(J \vec{x}_{3}\right)=1$ $(j=1, \ldots, m)$, is taken as the effective number of the degree of freetom in the data, $q$, where $\sigma^{2}\left(\Delta \hat{x}_{j}\right)=\sum_{k=1}^{q}\left(V_{j k} / \lambda_{k}\right)^{2}$.

5: Linear system is re-standardized by a new weighting matrix $W^{*}$, where $W$ is a covariance matrix for model parameters defined by $W \cdot V A{ }^{\mathrm{t}} \boldsymbol{V}^{\mathrm{t}}$.

6: For the re-standardized system, the decomposition theorem (III 3 ) is applied again, and a pseudo inverse matrix $H$ is produced as $H_{=}=\nu_{\Lambda}{ }^{1} U^{\mathrm{T}}$.

7: Optimal solution at this step is written by $\hat{x}=x^{0}+J \hat{x}$, where $J \hat{x}$ is defined by $\Delta \hat{x}=H \Delta y$.

8: Reliability of the resulting solution is evaluated by using the quantities, such as the resolution, expected error and effective data number, which are defined in section 3 .

If every perturbation of model parameters satisfies the condition, $\left|d \dot{x}_{y}\right| \leq$ $\sigma\left(\Delta \hat{x}_{j}\right)$, the successive iteration of inversions is accomplished at this step. When the condition for convergence is not satisfied, the process is returned back to the beginning of BLOCK II, after replacing the starting model by the optimal solution of the preceding step. 


\section{PROGRAM OF GEODETIC DATA INVERSION}

\section{READ IN INFORMATION FOR ANALYSIS}

a) Observed Data

1. P- and S-wave velocity and unit of length.

2. Number of triangulation points and bench marks.

3. Location of the stations.

4. Static displacements at the stations.

b) Presupposed conditions

1. Number of fault planes and independent model parameters.

2. Appropriate value of error coefficient.

3. Initial values of model parameters.

4. Matrix for constitution of a multiple-fault system.

5. Maximum allowable deviations of model parameters.

II. CALL SUBROUTINE (Coefficient Matrix)

1. Computation of theoretical displacements at the stations.

2. Computation of elements of coefficient matrix

III. CALL SUBROUTINE (General linear Inversion)

1. Construction of matrix equation.

2. Standardization of linear system.

3. Decomposition of the coefficient matrix.

4. Selection of adequate effective number.

5. Re-standardization of the linear system.

6. Construction of a pseudo-inverse of coefficient matrix.

7. Computation of the optimal solution at this step.

8. Evaluation of the reliability of solution (resolution, expected error and effective data number).

IF; Every model parameter converges to an assigned finite value no

RETURN; After replacing the starting model by the optimal solution at this step, go to Ir.

The maximum size of a linear system which can be treated by this program is 300 (data) $\times 90$ (fault parameters), and it depends only on the memory capacity of the computer. All of the computations involved were made on the HITAC 8700,8800 at the Computer Center, University of Tokyo. The computational time for the case of the six-fault model is about one hour to accomplish a successive iteration of inversions, which converged at the ninth 
step. The computer program for the geodetic data inversion is now available to all for use.

\section{Summary}

This study demonstrates that the method of geodetic data inversion developed in Part I provides us a useful tool to estimate the optimal fault-plane solutions of seismic events and evaluate their reliabilities from the static displacement data, through the analysis of crustal deformations due to the occurrence of the 1927 Tango earthquake.

In geophysical problems, it is particularly needed that the estimated results are quasi-stable against the variations of the presupposed conditions for analysis, such as the starting model, error coefficient and maximum allowable deviations. As to the present method, such a requirement is satisfied by introducing a process of re-standardization of a linear system using a predicted covariance matrix of model parameters.

Two types of measures, the resolution and effective data number, are used for evaluating the reliability of the resulting solution. It is not proper to take the resolution as a measure of reliability, unless the system is strongly over-constrained. When the system is not strongly over-constrained, it is very frequent that the parameter determined only from a few critical data is accompanied with a good resolution, which may be remarkably changed by adding a new effective datum to the previous data set. On the other hand, the effective data number, which indicates the number of effective data contributing to the determination of a model parameter, acts as a good measure of reliability, even in such a case.

In case of the Tango earthquake, adequate values of error coefficient are about 0.15 for the two-fault model and 0.10 for the six-fault model respectively. This suggests that the total effect of various deficiencies in the mathematical model on the surface deformations is less than $10 \%$, i.e., the actual displacement fields caused by seismic events are well interpreted within the residual error of $10 \%$ by the multiple-fault model composed of several rectangular faults in an elastic half-space.

On the basis of the analyzing results, two interesting conclusions are obtained:

i) Extension of two main faultings, the Gomura and the Yamada, almost coincides with the aftershock area.

ii) These two seismic faults constitute a system of conjugate faults caused by a single stress system of NW-SE compression.

The author is indebted to Dr. R. Sato and Dr. J. C. Savage for critically reading the 
manuscripts of the present series of Part I and II and offering many suggestions. My thanks are also due Prof. K. Kasahara and Dr. S. Hiyama for their useful comments.

\section{REFERENCES}

AlEWINE, R. W. and T. H. JORDAN, Generalized inversion of earthquake static displacement fields (abstract), Geophys. J. R. Astron. Soc., 35, 357-361, 1973.

Chinnery, M. A., The deformation of the ground around surface faults, Bull. Seismol. Soc. Am., 51, 355-372, 1961.

Jovanovich, D. B., An inversion method of estimating the source parameters of seismic and aseismic events from static strain data, Geophys. J. R. Astron. Soc., 43, 347-365, 1975.

KASAHARA, K., The nature of seismic origins as inferred from seismological and geodetic observations (1), Bull. Earthq. Res. Inst. Univ. Tokyo, 35, 473-532, 1957.

Kasamara, K., Physical conditions of earthquake faults as deduced from geodetic data, Bull. Earthq. Res. Inst. Univ. Tokyo, 36, 455-464, 1958.

Matsu'ura, M., Inversion of geodetic data Part I. Mathematical formulation, J. Phys. Earth, 25, 69-90, 1977.

Matsu'ura, M. and R. SAto, Displacement fields due to the fault, Zisin, 28, 61-73, 1975 (in Japanese).

Matsu'ura, M., K. Miyashita, T. Iwasaki and R. Sato, Strain and tilt fields due to the fault, Zisin, 29, 375-382, 1976 (in Japanese).

Matsuzawa, T., Study of Earthquakes, Uno Shoten, Tokyo, Japan, 1964.

NASU, N., A stereometrical study of the aftershocks of the great Tango earthquake with special reference to the mechanism of their occurrence, J. Fac. Sci. Univ. Tokyo, 3, 29-129, 1929.

Tsubor, C., Investigation on the deformation of the earth's crust in the Tango district connected with the Tango earthquake of 1927 (Part I), Bull. Earthq. Res. Inst. Univ. Tokyo, 8, 153-221, 1930a.

Tsubor, C., Investigation on the deformation of the earth's crust in the Tango district connected with the Tango earthquake of 1927 (Part II), Bull. Earthq. Res. Inst. Univ. Tokyo, 8, 338-345, 1930 b.

Tsubor, C., Investigation on the deformation of the earth's crust in the Tango district connected with the Tango earthquake of 1927 (Part III), Bull. Earthq. Res. Inst. Univ. Tokyo, 9, 423-434, 1931.

Tsubor, $C$., Investigation on the deformation of the earth's crust in the Tango district connected with the Tango earthquake of 1927 (Part IV), Bull. Earthq. Res. Inst. Univ. Tokyo, 10, 411-434, 1932.

Walsh, J. B., Dip angle of faults as calculated from surface deformation, J. Geophys. Res., 74, 2070 2080, 1969. 